\title{
Counterfeit Alcohol Distribution: a Criminological Script Network Analysis
}

\begin{abstract}
This paper analyses a series of subsequent and connected investigations by a domestic European regulatory on the network of distribution of counterfeit alcohol across two jurisdictions. The analysis mixes script analysis, a narrative framework for enhancing the understanding of how crimes unfold and are organized, with multi-node multi-link social network analysis, to observe the social structure in which crime scripts take place. We focus our attention on the key players that occupy strategic positions within the network of the crime commission process, from where they overview and control the various phases (scenes) and perform brokerage activities across the scenes, and on strategies of concealment of illicit products beyond the façade of legitimate business. Our findings indicate that actors in charge of managing the proceeds of the criminal activity are also the ones better positioned to monitor the entire process. The overall structure of the criminal network shows a good level of resilience and efficiency, although actors do not adopt common traits of a criminal lifestyle that facilitate secrecy and covertness. We believe that, by shifting the analysis from the nature of the group organization to the network of links between all the aspects of a crime commission process, the organizational structure and its weakest links become more detectable, easier to compare across proto- and meta-scripts, and ultimately more prone to situational preventive measures.
\end{abstract}

\section{Keywords}

Counterfeit alcohol, criminal networks, multi-link networks, multi-mode networks, script analysis, social network analysis

\section{Introduction}

Counterfeit alcohol production and distribution is a high priority concern for EU and domestic authorities. A report from Europol and the Office for Harmonization in the Internal Market (OHIM 2015) argues that despite the worrying growth in counterfeiting, the rise of domestic production in several EU countries and the damage it does to businesses and consumers, there is no comprehensive picture of its criminal dimension and dynamics. This paper presents the results of the first study, to our knowledge, of a criminal case related to the international distribution of counterfeit alcohol. Previous studies have looked at the distribution of other counterfeit products, like tobacco (Antonopoulos and Hall 2016; Di Nicola and Terenghi 2016; Kupka and Tvrdá 2016), olive oil (Lord et al. 2017), pharmaceuticals (Lavorgna 2014a); or at the composition of surrogate and illegal alcohol in Estonia and Russia (Lang et al. 2006; McKee et al. 2005), and the extension and consequences of its consumption (Kotelnikova 2014; 2017). However, to date none have investigated the routes and structure of counterfeit alcohol distribution across European jurisdictions.

A common underlying perspective of the public authorities is that counterfeit crimes are predominantly pursued by organized crime groups and that these in turn need to be 
disrupted due to the inherently illicit market contexts of their activities. However, it has been argued that the problem of organized crime groups is in the concept itself (Edwards and Levi, 2008). Our paper discusses the appropriateness of referring to organized crime groups when studying transit crimes (i.e., criminal trafficking activities, see Kleemans 2007). In doing so, it contributes to the on-going debate about the political and practical reasons and consequences involved in adopting an organized crime groups framework (Ashby 2015; Lavorgna and Sergi 2016), and the alternatives in hand. Shifting analytical focus away from a preoccupation with the attributes of organized crime groups and towards the nature of illicit trading relations, practices and networks in 'grey' or 'dirty' markets allows us to better understand the routine and rational practices of these traders in their pursuit of crime as enterprise (Edwards and Gill, 2002: 204).

To do this we combine social network analysis with script analysis, a fruitful mix of methodology that has already produced significant results in the literature (Morselli and Roy 2008; Bright and Delaney 2013). In doing so we aim to increase our understanding of the possible recurrent patterns of criminal activities in the specific sector of counterfeit goods, and to facilitate the task of guardianship in intervening and disrupting such criminal activities. Our argument is that it is more analytically useful to shift the narrative from a focus on organized crime groups to the identification of the tasks and opportunities that drive criminal activities and the efficiency and resilience of the networks involved in the crime commission process. This in turn enables a more valid comparison of 'scripts' across criminal categories as well as the identification of the procedural steps where preventive intervention might take place.

In order to achieve our goal, the first section discusses the state of art of the literature on transit crimes and counterfeit goods; on the legitimacy and non-legitimacy of the contexts in which such criminal activities operate; on the application of crime script analysis to identify the stages of the crime commission process and the actors, resources and decisions involved in each stage; and on the analytical advantages of combining script analysis with social network analysis, in particular with a multi-mode, multi-link network approach (Carley 2003; Schwartz and Rouselle 2009; Morselli 2010) where nodes can represent various entities (people, organizations, resources, locations) involved in the scene, and the ties represent the type of actions performed.

The second section (Data sources, research questions and methodology) introduces the research objective and questions that guide our study, illustrates the data sources and the data manipulation we used to obtain our material, details the methodological strategies adopted, and presents the case studies under analysis. The following three sections are dedicated to data analysis. We first perform a script analysis of the available cases to identify the crime scenes, the actors and their resources; the sequence of actions and decisions before, during and after the criminal activity at all stages of the crime commission; the tasks that need to be performed to commit these activities; and the range of places where they are performed. We subsequently organize this information in a multi-mode, multi-link network.

We then collate script and social network analysis, to identify the key players that occupy strategic positions within the network of the crime commission process, from where they 
overview and control the various phases (scenes) and perform brokerage activities across the scenes. An innovative aspect of the paper is that we extend brokerage analysis, previously adopted by Morselli and Roy (2008), to observe not only the brokerage positions of criminals in the network of relationships with other individuals, but also the various types of connections that such criminals maintain across places, business enterprises, and resources. Our analysis identifies the actors whose position suggests a central and managerial role in organizing the distribution of counterfeit alcohol in the two jurisdictions and advances possible interpretations for the network structure.

We discuss the findings by reflecting upon the advantages of adopting a multi-mode, multilink network, and of categorising different brokerage roles (Gould and Fernandez 1989) for the identification of its weak links. It is our contention that the criminal group under analysis shows an efficient and resilient network that requires a good level of organization, ramifies widely across two countries, and hides non-legitimate activities behind otherwise legitimate actors and businesses practices (Benson and Simpson 2015). We argue that it is the crossing points between licit and illicit activities that the network shows its vulnerable spots, where situational prevention measures may be enforced.

\section{State of the art: Counterfeiting and organized crime}

The International Trademark Association (INTA) defines counterfeiting as the practice of manufacturing, importing/exporting, distributing, selling or otherwise dealing in goods, often of inferior quality, under a trademark that is identical to or substantially indistinguishable from a registered trademark, without the approval or oversight of the registered trademark owner'. An important aspect of the counterfeit market is that in the process of trading counterfeit products, criminals may conceal their activities or their profits behind legitimate business.

Because of the complexities involved in the production and distribution of counterfeit goods and its potential ramification into legitimate business, counterfeit crimes have been associated with the activities of organized crime groups. Indeed, counterfeiting can be part of the portfolio of criminal organizations (Campana 2011), but the association of serious and complex crimes to the work of organized groups is often the outcome, at least in the UK, of a rhetoric narrative that defines the seriousness of a crime according to its association with organized groups in order to redirect resources, but without having robust empirical evidence (Lavorgna and Sergi 2016). This common tendency may imply some unintended and counter-productive consequences, including the risk of overestimating the homogeneity of offending career and crime processes, the misplaced allocation of public funding, the authorities' loss of credibility, the potential interference with suspects' rights, and the implementation of wrong interventions, for example the avoidance of preventive measures in favour of investigations and punishment (Ashby 2015).

The absence of empirical evidence of the organized nature of serious crimes is partially due to the lack of a robust definition of what exactly organized crime is (Albanese 2000; Finckenauer 2005). The official definition of the UK government (section 45 of the Serious Crime Act 2015), for example, is so broad that it tends to incorporate most of the criminal offences if they are committed by three or more people, who associated over an extended 
period, with the intention of obtaining material profits. Ashby (2015), in his research on metal theft, departs from the focus on the categorization of criminal association and prefers relying on the operational definition adopted by practitioners investigating metal theft cases, who concentrate on the sophistication of the criminal procedure, the ability to travel across the country and the previous involvement of the criminals in other organized crime activities, like drug trafficking and counterfeit currency.

By adding the nature of the activities carried out by criminals to the definition of organized crime, alongside the features of the groups' association, we can focus attention not so much on the individuals involved but on the crime commission process. The focus on the context of criminal activities has been successfully embraced by the so-called environmental criminology and its practical application of situational crime prevention theory, directed to understand the circumstances of a specific crime and the opportunities available to commit it, to identify practical ways or reducing such opportunities and minimize the crime's harm (Eckblom 2003; Bullock et al. 2010). Situational crime prevention theory identifies the potential points of intervention to disrupt such opportunities by breaking down the procedure of crime into sequential scenes, or crime scripts.

Crime script analysis, grounded in a rational view of human behaviour, was first developed in cognitive sciences (Schank and Ableson 1977) and adopted in criminology by Cornish (1994: 160) as 'a way of generating, organizing and systematizing knowledge about the procedural aspects and procedural requirements of crime commission'. It specifically identifies the scenes of the crime commission, the decisions, actions and resources required at each stage, and the cast of actors involved in these stages. Scripts therefore provide a way of understanding the logistic steps (not necessarily linear or sequential, allowing for flexibility and actor innovation) that take place across different scenes. Within each 'scene', can be found different permutations of the 'facets' that make up the different ways the behaviours can be accomplished. The deconstruction of crime in a series of successive tasks allows for the planning of crime prevention by mapping suitable intervention mechanisms within the situations in which criminal activities take place.

Crime script analysis considers decisions and tasks as crime specific (Leclerc and Wortley 2014: 3), but it also offers a way to produce potentially comparable patterns of crime procedures based on the repertoires of behavioural sequences (Leclerc and Wortley 2014; Chiu et al. 2011). Leclerc et al. (2011) suggest four levels of generality of crime scripts on which they can be compared: the meta-script level comprises all crimes within a classification (e.g., transit crimes). The proto-script distinguishes different subgroups within an offence (e.g., for transit crimes, traffics that involve humans, animals, or goods). The script level subdivides the offence into categories according to a specific dimension relevant for situational prevention (e.g., type of good, situation, and modus operandi). The track level provides a more detailed study of offending within the context and specifications of the situation in which the crime is committed, as well as representing the level at which situational crime prevention is commonly practiced (Leclerc et al., 2011: 212). Systematising the information of the track level into more general script level categories allow us to compare the specificity of scripts across proto-scripts, and ultimately meta-scripts, to be able to observe common patterns across different types of criminal activities and suggest 
preventive intervention that go beyond single crimes and potentially apply to a whole class of offences.

Hancock and Laycock (2010) go further and differentiate the primary criminal act (the offence process) from the criminal lifestyle and the participation in criminal groups and networks. These additional features of crime scripts can be relatively stable crime facilitators. Lifestyle features include the pursuit of anonymity, the disposing of large quantity of cash, the use of unregistered vehicles, pre-paid phones and false bank accounts, and the corruption of legitimate business. The criminal group can present different levels of organization, from highly permanent and hierarchical ones to the loose and temporary networks for a specific crime purpose. It can also outsource tasks to other associated groups or individuals with specific skills and resources, like any legitimate business would do (Hancock and Laycock 2010).

The various potential structures of relationships of criminal groups (for example, hierarchical vs. sparse) can be observed with a social network analysis approach. Social network analysis has become increasingly popular in criminology since the 1990s (Varese 2010), especially focusing on the conceptualization of network efficiency. Because of the criminal nature of its activities, actors involved in the crime process need to make sure that their work is hidden enough from the authorities (need for secrecy) but not to the point that it may hamper the delivery of the intended actions (need for efficiency, see Morselli et al. 2007).

A first step in the literature therefore has been to precisely define what efficiency is in a criminal network, and how to measure it. Bouchard (2007) proposes to equate efficiency with network resilience, envisioned as retaining the capacity to act. In his view, resilience depends on the vulnerability of the network, as in the likelihood of being damaged by removal of certain parts of it (actors, ties); on the elasticity of the network, as in the ability to return to a previous state after disruption (for example, by replacing actors or reestablishing ties); and on the adaptivity of the network, as in the ability to modify according to the circumstances (for example, functioning without certain actors or ties). Other scholars proposed various ways to operationalize network resilience, as effectively summarized by Oliver (2014): networks are more effective if they have access not only to actors and ties, but also to resources, and if these actors, ties and resources are multiple (Krebs 2002); if they can count on structural equivalent actors (Klerks 2001; Koschade 2006); and if they are embedded in overt and legitimate networks (Gimenez-Salinas Framis 2013). These properties are believed to diminish vulnerability and increase elasticity and adaptivity.

However, when tackling the empirical analysis of criminal networks, the literature seems to concentrate only on one type of actors, usually individuals. Carley has already challenged this limit by showing the importance of adopting a multi-mode approach that considers not only who is connected to whom, but also who has what resources or skills, who is doing what, and where these people are (Carley 2003). She proposes a meta-matrix that summarizes the various types of networks emerging from structures where nodes can be people, organizations, resources, and events (Carley 2003: 172) and ties can link these different actors in various ways, for example by transferring skills, timing events, organizing 
groups, managing memberships and recruitment. In this way we can not only observe the relational structure of the criminal group, but also map the lifestyle features that each part of the network may provide to the criminal process, together with its geographical extension. A similar approach has also been proposed by Bright et al. (2015).

There are several points of connection between crime script analysis and the multi-mode and multi-link network approach. Both observe the crime process as a set of organized tasks that evolve over time and adapt to the contextual contingencies. Crime scripts can be deconstructed to identify vulnerabilities in the crime commission process; likewise, criminal networks can be mapped to detect weak (or strong) links and actors. Both crime scripts and criminal networks are crime specific, but at the same time can produce generalizable repertoire and behavioural scripts and relational structure. It was then an expected consequence that scholars started merging the two approaches.

Morselli and Roy (2008) offer a valuable example of this combination. In their view, networks with a loose structure that is connected by people in brokerage positions are more likely to be efficient than rigid hierarchical networks. Conversely, the removal of such connecting people diminishes the flexibility of the criminal process, reducing coordination opportunities for the whole network. They propose to use betweenness centrality (Freeman 1979) and Gould and Fernandez brokerage roles (1989) to identify brokerage roles: while betweenness is useful to identify actors that keep the whole network connected, Gould and Fernandez (GF) brokerage roles are valuable to identify the actors who liaise between different scenes of the crime scripts, facilitating collaborations between people involved, but also the feasibility of alternative criminal routes. Alternative routes are defined, in script analysis, as substitutable facets within a scene, where the combinations between facets and across scenes are referred to as permutations within the script. The higher the level of permutation of a script, the more flexible and therefore efficient a criminal procedure is believed to be (Morselli and Roy 2008: 74; Cornish 1994).

The innovative proposal of this paper is to extend Morselli and Roy's approach by substituting the social network of actors that are casted across scenes by a multi-mode, multi-link network (Carley 2003) that takes into account not only the individuals, but also the organizations, the resources and the locations where criminal activities take place. Furthermore, we include various types of ties: personal (being friends or relatives); transport and logistics (selling and receiving goods); selling and buying goods; business (owning or having access to resources); and other type of ties like paying for transactions and being otherwise linked to the cases under analysis. By adopting a multi-mode, multi-link network approach, we can take into account the group structure and criminal lifestyle involved in the organization of the distribution of counterfeit alcohol, but also, as will become clear from the description of the case studies in the next section, the various cases of counterfeit alcohol investigated at different times and in different locations. The temporal aspects of these investigations also suggest how the same criminal system may be organized around substitutable facets of the same script, increasing the resilience of the whole network. 


\section{Data Sources, research questions and methodology}

The case studies analysed in this paper were provided by a European regulator responsible for food safety, food fraud and food crime. The regulator is investigating a number of related cross-border cases involving the distribution of counterfeit vodkas and wines (Dale's and Viin vodka ${ }^{1}$ ) and provided us with access to extensive and detailed investigation case files, which consist of approximately 150 documents related to:

- Offenders' offline profiles, obtained via desk investigations: the regulator gave us a detailed spreadsheet with all the available information about everyone investigated in the cases, including details of their past and current addresses, past and current business activities, properties and vehicles owned or purchased. This information was used to construct each suspect's lifestyle, and to find evidence of its criminal aspects (for example, being connected to people previously involved in criminal activities, being involved in previous criminal activities themselves, undeclared properties ownership, and the like).

- Offenders' social media profiles, obtained via desk investigations: these include social media contacts, pictures, comments and tags that link suspects together. This information was used to reconstruct the structure of personal relationships between suspects.

- Intelligence reports, consignment and delivery data, communications with logistics firms, communications with brands/manufacturers, photographic evidence from the locations of the criminal offences, website and social media adverts, seizure data, press releases and media reports of seizures and convictions. This information was gathered by the regulator in collaboration with local authorities (Irish, British, Italian and French police, Revenue \& Custom) and provided detailed data of the primary criminal acts.

- Email exchanges between the regulator and local authorities collaborating on the cases. This information was essential for the understanding of the international ramifications of the cases, but also highlighted the unavoidable limits of investigations that involve independent jurisdictions with different scopes, resources and power.

The case descriptions and the script analysis are reported (in the same way as in this article see the following section) in Lord et al. (2017), where we also discuss situational prevention measures in detail. In Spencer et al. (2018) we concentrate on the definition of the middle market in counterfeit alcohol and the structure of the 'illicit' market. Here we want to focus specifically on the combination of script and social network analysis as a method to investigate the organized structure of the criminal group, its efficiency and resilience. Preliminary results of our analysis were discussed in subsequent meetings with the team of investigators and suggested potential directions of the investigation. The regulator followed our advice and was able to discover further suspect lifestyle characteristics of the individuals involved in the offence, reinforcing the validity our analysis.

\footnotetext{
${ }^{1}$ All names of individuals, organizations, and where possible, locations of seizures are fictional in order to anaonymize the real actors.
} 
Our data have some limitations. First, all the information was acquired from the regulator in charge of the investigation, thus some data (for example, relationships between the criminals, or available resources) might be missing for the simple reason that they were not observed. Second, the regulator is an institutional organization with specific aims, resources and priorities, that mainly focus on the consequences of distribution and consumption of counterfeit goods for public health and tax evasion. This, as already noticed by Di Nicola and Terenghi (2016), Antonopoulos (2008) and Hobbs and Antonopoulos (2014) implies that the regulator may have fewer resources available for investigating certain aspects of the crime, for example production, because available resources are directed toward more compelling priorities. Also, the investigated offences span different European jurisdictions, therefore the regulator must rely on the collaboration of other institutional organizations with different aims, resources and priorities which may slow down the investigations. This was particularly evident when analysing the email exchanges with cooperating authorities, where in some cases further actions were required but not pursued at the time of the analysis.

The research was funded by the University of Manchester Research Institute and Alcohol Research UK, took place over a nine-month period from January 2016 to September 2016 and was guided by the following questions:

1. Who are the actors and what are the resources and locations of the criminal process under analysis? How are they related to each other?

2. What are the procedural steps required to commit the crime, which emerge from the analysis of the available data?

3. In which stages was the criminal activity concealed behind legitimate practices, and what inferences can we draw in regard to the legal responsibilities of the actors involved?

4. How do the identified scripts resemble/differ from scripts of other similar crime scenes?

5. Can we identify the roles of the actors involved in the criminal activity, and can we draw any conclusion about the nature of the organization of such activity?

To address these questions, the data were firstly qualitatively analysed to identify the procedural steps of the crime commission (scenes), and to distinguish the participating actors (including people, organizations, locations and resources), the relationships between actors (existence and type of relationship), the location of actors, indications of criminal lifestyle (previous convictions, ownership of unregistered vehicles and phones, movement of large sum of cash), and the 'scene(s)' to which the actor belonged.

The data were coded in Excel and imported into UCINET (Borgatti, Everett and Freeman 2002) where a multi-node, multi-link network analysis (Carley 2003) was carried out. In line with Morselli and Roy (2008) we calculate betweenness centrality (Freeman 1979), which counts how many times an actor lies on the shortest path between each pair of nodes in the network and normalize it by dividing it by the maximum possible betweenness expressed as a percentage; then we calculate GF brokerage roles across different scenes. Brokerage role analysis allows us to observe not only which actors are better positioned to connect the 
network, partially gathered by betweenness centrality ${ }^{2}$, but also which specific scenes of the crime each actor spans, and what type of brokerage role s/he exercises. Gould and Fernandez (1989) identify five types of brokerage roles, according to the direction of the ties and the groups the actors belong to. In a situation where $A$ sends a tie to $B$ (broker) who sends $a$ tie to $C$ and there are no ties between $A$ and $C$, the five possible brokerage roles of $B$ are:

- Coordinator: A, B and C belong to the same scene. Coordinators are brokers in charge of managing people and resources within the same scene, for example coordinating delivery or collection.

- Consultant: $\mathrm{A}$ and $\mathrm{C}$ belong to the same scene, while B belongs to a different one. Consultants can provide resources from one scene to another, for example thy can pay for costs of logistics without being directly involved in it.

- Gatekeeper and/or Representative ${ }^{3}$ : A (or C) and B belong to the same scene, while C (or A) belongs to a different one. Gatekeepers control the incomings/outgoings of resources and/or information within the scene they belong to.

- Liaison: all the actors belong to different scenes. Liaison are likely to be people with an extensive overview of all the procedural steps of the crime.

\section{The case studies ${ }^{4}$}

North case (UK)

In September 2013, 26 pallets containing over 17,000 litres of counterfeit Dale's Vodka were seized at North port in the UK. The consignment was being transported by a haulage company (Haulage Co.) from a storage facility located in Ireland owned by Patrick. Its destination was two companies in the UK: NE Grocery Ltd and Food Wholesalers Ltd. Haulage Co. had sub-contracted the delivery from an Ireland-based logistics company (Transport and Logistics Ltd), which, in turn, had sub-contracted the delivery from $A B C$ Logistics, a logistics and freight forwarding company. The arrangements for the collection and delivery of the pallets were made by James, and payment of $£ 1,200$ to $A B C$ Logistics was made by Phillip, both of whom were based in the UK.

\section{Delivery Ltd Case (UK)}

In April 2014, 1000 bottles of counterfeit Dale's Vodka were seized from Food Wholesalers Ltd, a company owned by Paul. The following day, in the same area, 120 bottles of the same alcohol were seized from John, as he was unloading them from his car outside his house. The bottles that were seized from Food Wholesalers Ltd and from John's car had the same identification numbers embossed on the base, and the same counterfeit caps and labels, as the bottles from the North seizure.

\footnotetext{
${ }^{2}$ The difference between the two measures consists in the fact that, whereas betweenness centrality counts the number of times a node lies on the shortest path (geodesic) between every pair of nodes in the network, Gould and Fernandez brokerage roles are a localized measure of structural holes.

${ }^{3}$ When ties are undirected, as in our case, the gatekeeping role is equivalent to the representative role.

${ }^{4}$ This section and part of the next section (Script analysis) have already been published in Lord et al. (2017).
} 
The counterfeit vodka had been sent to Food Wholesalers Ltd by David, the owner of Delivery Ltd, a courier firm based in Ireland. It was addressed to MB Testing, a MOT testing centre, whose mechanic told the driver to take it to Food Wholesalers Ltd. David sent the counterfeit vodka through Parcel Network, which had been delivering two pallets to the MB Testing address on a regular basis since October 2013. The two pallets that were seized at Food Wholesalers Ltd had been dropped off at the Parcel Network office by Delivery Ltd, for onward delivery. This may have been done by David himself, or by one of his employees (Michael and Graham).

Parcel Network represents a network of several individual Ireland-based transport companies. One of these companies, Crossways, transported the consignment destined for Food Wholesalers Ltd from the Parcel Network office in Ireland to a transport hub in the UK. Its onward transportation to its final destination was arranged by Freight Inc., an international freight network, whose network members include Crossways and Bard Transport. Bard Transport took the pallets of counterfeit vodka to MB Testing. Parcel Network does not require its customers to advise it of the contents of their consignments, and the pallets of counterfeit vodka boxes were completely wrapped in black plastic.

David, the owner of Delivery Ltd, has also sent a number of deliveries via Parcel Network to other addresses in the UK, including NE Grocery Ltd (also a destination of the counterfeit vodka seized in the North case), Joes Café and Seafood Supplies, Storage Solutions, Wines and Spirits Ltd, William's private address, and Gary Smith Motors. It has not been confirmed that these consignments involved counterfeit alcohol.

\section{Rural case (Ireland)}

In April 2014, 20 cases of counterfeit Dale's and Viin vodka were seized in a van in the south of Ireland. The markings on these bottles matched those in the North Case and Food Wholesales Ltd seizures. There are a number of evident links between the three cases. Firstly, Food Wholesalers Ltd is a delivery destination for both the North and Delivery Ltd cases. There are links between the bottles, caps and labels in all three cases, indicating they come from the same source. There are also personal links: Tom, one of Philip's drivers, is friends with John on Facebook, and John is friends on Facebook with Stephen and Sean (see next subsection).

\section{Further links and seizures}

In July 2014, 142 cases of counterfeit wine were seized from an address in a south city in Ireland. They had been bought from Sean by Richard via an advert on the DoneDeal website; Richard had previously bought wine from Sean in May 2014. Both orders were sent to Richard by David via Parcel Network. Sean met Richard in a local hotel to be paid for the wine, and to offer him to purchase some vodka. Stephen, Sean's brother, was stopped at the airport and a large amount cash was confiscated, which was believed to be the proceedings of alcohol sales. He also has a fake Linkedin profile and he is connected via Facebook to David, John, and John's brother, Andrew. 
There have been a number of seizures of counterfeit vodka and wine in the UK and Ireland over recent years related to points of disposal, that is, it was found at individuals' addresses (Mark, Helen), or being sold in shops (Localshops, ShoeShop) or licenced premises (Bars), or by individuals making sales to associates (Richard, John) or on social media or selling forums or websites like DoneDeal (that is, Sarah, Peter). There is no clear evidence yet of linkages between all these seizures, but it does demonstrate the wide geographical spread of counterfeit alcohol distribution.

\section{Script analysis}

Script analysis identifies five specific 'scenes' of distribution: collection, logistics, delivery, disposal, proceeds/finance. Within these 'scenes' there are various 'facets' (that is, permutations of ways of accomplishing the enterprise).

\section{Scene 1: Collection}

In the North case, the counterfeit alcohol is collected and transported from the storage point owned by Patrick to two final destinations, and the collection is organized by James. In the Delivery Ltd case David is contracted to collect and transport the product from the storage point to the local delivery hub ahead of transnational transportation. We consider James, Patrick and David as belonging to two facets of the same scene. Official paperwork is provided to the subsequent logistics company, making the consignment look like an otherwise legitimate transaction/contract. Once the consignment has been taken on by the logistics company, the illicit product is no longer under the direct control of the criminal enterprise. At this point, a first-stage deception has occurred because the legitimate logistics company is the victim of dishonesty and/or misrepresentation.

\section{Scene 2: Logistics}

The second scene of the distribution script involves the transportation of the illicit product through three primary phases: 2a. local logistics (that is, the movement of product from the courier delivery point domestically to the port or point at which the product begins the cross-jurisdictional logistical path); 2b. transnational logistics of the product across borders; 2c. local logistics in the target jurisdiction as the product moves via logistics depots before delivery to the designated receiver. We consider ABC Logistics - Transport and Logistics Ltd Haulage Co. and Parcel Network - Crossways - Freight - Bard Transport - Delivery Ltd as two facets of the logistics scene. All the transport and logistics firms are again legitimate commercial enterprises.

\section{Scene 3: Delivery}

The third scene of the script involves the return of the illicit alcohol into the control of the criminal enterprise. In the North case the delivery was made to NE Grocery Ltd and Food Wholesalers Ltd. In the Delivery Ltd case deliveries were made in the first instance to MB Testing, where they were diverted to Food Wholesalers Ltd; other deliveries were made by David to NE Grocery Ltd, Joes Café, Seafood Supplies, Storage Solutions, Wines and Spirits Ltd, Gary Smith Motors and William. We assume that these locations represent alternative 
facets of the same delivery scene and that the actors receiving the product must be 'trusted accomplices'. We consider collection and delivery as distinct scenes from logistics because in the latter the consignments are concealed in the distribution system of legitimate haulage companies, while in the former they are under control of the criminal actors. They are also different from each other as they happen in two different European jurisdictions.

\section{Scene 4: Disposal}

The fourth scene of the script is the distribution of the illicit product to multiple consumer outlets. At this point we see a second stage of deception because the buying outlets, though more likely the consumers of alcohol in licenced premises, are the victims of deception and misrepresentation. It may be reasonable to argue that some form of concerted ignorance or wilful blindness occurs as vendors, purveyors and consumers seek to buy cheap booze. The numerous places of disposals, as indicated in the description of the cases (North Somerset, Norfolk, Warwickshire, Bridgend, Bournemouth, Rotherham, Northampton, Sandwell, Stockton on Tees), together with individuals (Helen, Sarah, Richard, John, Peter, Mark) and online markets (DoneDeal) are all alternative facets of the disposal scene.

\section{Scene 5: Proceeds / finances of crime}

This fifth scene is not necessarily the last scene but more likely occurs at various stages, particularly in scenes 1 and 4 . Those implicated (criminal) actors will need to:

- $\quad$ pay for the business transactions, for example buying or producing the alcohol and paying the invoices of haulage companies;

- conceal and control the movement of the proceeds;

- launder the money into usable assets or reinvest it.

In the North case, Philip is the only actor associated with payments, whereas in the Delivery Ltd case Andrew, Sean and Stephen are all involved in finance. These actors are therefore considered alternative facets of the same scene.

Table 1 summarizes the participation of the various types of actors to each scene, their actions and the resources they provide (where known/applicable), together with the classification of actions and resources into Primary criminal act, Lifestyle and Groups/Networks (Hancock and Laycock 2010).

[here Table 1]

\section{The multi-mode, multi-link network of counterfeit alcohol distribution}

After assigning actors, organizations, locations and resources to scenes (Table 1), we proceed to construct the network of the distribution of counterfeit alcohol. We include in the network every actor, alcoholic product, organization and location that was mentioned in various capacities in the record of the three investigation cases described in the second section. Each of these entities constitutes a node with an attribute indicating their involvement in respective scenes. Even though some actors participate in more than one scene (see Table 1), for the analysis of brokerage roles we assign each of them to the scene 
they contribute most ${ }^{5}$. We then classify the type of tie that links these nodes: this can be a personal tie (that is, family relationship, friendship on Facebook); a transport/logistic tie (that is, driving a van, ordering/collecting/receiving/sending goods); a selling tie (that is, buying or selling counterfeit alcohol); a business tie (that is, owning a firm, subcontracting); or any other tie (that is, paying for a transaction, having any other involvement with the case). All ties are undirected.

The network thus constructed has 68 actors and 129 ties and it is illustrated in Figure 1, where different shades of grey indicate the type of tie and the scenes nodes belong to, while shapes differentiate between types of actors. Table 2 reports the meaning of colours for scenes and ties, and of the shapes for nodes.

[here Figure 1]

[here Table 2]

At a first glance we can see from Figure 1 that the network seems to separate scene 1-3 from scene 4. Most of the selling ties (grey) are concentrated on the left side of the network, while the transport/logistic ties (darker grey) appear only on the right side. These transport and logistic ties are also locally organized. Collection (scene 1) is also locally organized, with James and Patrick in charge of the task for the North case and Graham and Michael involved in it for Delivery Ltd case; Tom and David lie in between the two cases and seem to be involved in scene 1 in both cases. Likewise, international transport (scene 2) is outsourced to different logistic networks in the two cases. The distribution scene (scene 3) shows some interesting aspects: it seems that in comparison with the North case, David multiplied the facets by breaking down the main consignment into multiple destinations. The multiplication of facets could be a strategy adopted by David to shift attention from the main points of delivery of the North case (NE Grocery Ltd and Food Wholesalers Ltd) to a large list of alternative routes which are likely to be less detectable by authorities or to attract the attention of legitimate couriers.

The links that connect collection (scene 1), logistics (scene 2) and delivery (scene 3) are worthy of attention, because they are the points at which concealment is likely to happen, and where the illegal consignments are first entrusted to (scene 1), and then recollected from (scene 3 ) the legitimate network of logistic firms. Because logistic companies are not required to check the content of parcels, once the illegal consignments are embedded in the licit chain of local and transnational transport they become highly invisible to the authorities. As we have said, the use of legitimate businesses seems to provide an optimal solution for transporting counterfeit alcohol across national borders. However, the incorporation into legitimate networks also represent a risk for the criminal organization: if discovered, it is easy for authorities to track the reverse process of collection and delivery, and initiate investigations that involve the licit business in charge of storing the alcohol at beginning and ending point of delivery. On this, our actors do not seem to display the lifestyle trait of pursuing anonymity, as they all use their real names and businesses details to manage the transactions.

\footnotetext{
${ }^{5}$ This is because the UCINET routine that calculates GF brokerage roles across scenes requires each actor to belong to a unique scene.
} 
Scene 4 is also interesting because it shades a light on the potential extension of the sales market of counterfeit alcohol. Although a few grey lines are embedded on the right side of the network, most of them lie on the left side, with only two actors in between (Sean and Richard) and a location (Stockton on Tees). Peter and Sarah also link the sale of Viin Vodka to the sale of Wine, and a website (DoneDeal) seems to be used for online purchases. The lack of connection very likely depends on the covertness of the network: on the one hand we probably see only part of the full network of sale simply because investigations have not followed the potential routes yet (because the investigations are still ongoing, or because of the lack of resources); on the other hand it might signal an intentional strategy of keeping the disposal scene as detached as possible from the delivery scene, to avoid the chances of being traced if alcohol is discovered in scene 4 .

\section{Script and networks: Identifying key actors across scenes}

Table 3 reports the values of betweenness (above 200) and normalized betweenness (more than $10 \%$ ) for the most central actors: the main ones are the people involved in proceeds, indicating the essential role of this scene for the organization of criminal activities. Disposal places and people also appear in the top scores, together with Food Wholesalers Ltd, where alcohol is stored.

[here Table 3]

Table 4 illustrates the number of times individuals occupy a specific brokerage position across scenes, together with the total number of brokerage roles.

[here Table 4]

First, we note (Figure 1) that only John, Sean, Andrew and Steven are all personally connected via either family or friendship ties (groups and networks). David is introduced into the network via Steven, but is otherwise not connected to the others. His role is central in the delivery organization (primary criminal act), where he provides resources and knowledge linked to his legitimate business (lifestyle). His score on betweenness is not one of the top ones, as in the case of Phillip and Sean, who are both involved in the proceeds scene. Phillip is unemployed and previously involved in other alcohol seizures (lifestyle), where he paid for some of the business transactions (primary criminal act). Sean is in charge of selling the alcohol (primary criminal act) and is the owner of a property abroad, although we cannot assume that it was bought with laundered money. Other actors scoring high in betweenness centrality are Peter and Sarah, who were found guilty of selling alcohol (primary criminal act).

Gould and Fernandez brokerage measures produce a different ranking of nodes, and highlight the role of further actors in the network. Phillip and Sean both rank at the top, while Peter and Sarah drop down the ranking. David now ranks first, followed in third position by John, who is involved in disposal. John is Andrew's brother and was found in possession of a large number of bottles. Interestingly, Andrew and Steven, both involved in proceeds, do not score high on either betweenness or GF brokerage roles, despite being two key actors in the crime procedure. Andrew is the only person with known links to local 
criminality (lifestyle) and was believed to receive money from the sale of alcohol. Steven not only connects David to the other central actors (groups and networks), but he had also a large quantity of cash confiscated at the airport (primary act).

Whereas Table 4 only indicates only the number of times actors are found in a specific brokerage position, Table 5 specify across which scenes actors exercise brokerage activities (we analyse only the role of people with the highest number of brokerage roles). Black cells indicate coordination roles, dark grey cells consultancies, light grey cells gatekeeping/representative positions, and white cells liaison roles.

David, in charge of collection and delivery, presents the highest number of brokerage roles within and between these two scenes, but he also acts as a gatekeeper and liaises across all the other scenes. His documented role entails collecting the consignments, assigning them to international logistics companies and organizing the final delivery. This overt role is easily concealed behind his legitimate activity as a courier, but it is also the weakest link in the whole crime commission procedure, because once the consignments are discovered, the trail of paperwork, which are not anonymized, traces his involvement and responsibilities. He could potentially pretend to be unaware of the nature of the consignments, but his personal link to Steven and his brokerage activities across all the scenes reinforce the suspects of his criminal involvement.

Philip is involved in proceeds, but he does not occupy any coordinating or gatekeeping role connected to this scene. He instead liaises and consults across all the other scenes, indicating an important managerial role in the crime commission process. John, involved in disposal, liaises from collection to delivery and proceeds, and acts as a gatekeeper between disposal and all the other scenes. Although his brokerage activities are less frequent and exhaustive compared with Phillip's, their profiles complement each other, and together they have an overall overview of the all the phases of the criminal activity. Finally, Sean's position indicates that his role concentrates mostly on disposal and proceeds (he belongs to the proceeds scene), making him a very important actor in the network, especially in regards of the financial aspects of the crime.

[here Table 5]

\section{Discussion}

In discussing the finding of our analysis, we first notice that the network of distribution and sale of counterfeit alcohol across Ireland and the UK is organized around two main groups: collection, logistics/transport and distribution on one hand, which seem to be locally organized, and sale on the other hand, which branches out in Ireland and the UK. Given the fact that the transport route from Ireland to the UK had been discovered, we suspect that the route established in the Delivery Ltd case could be an alternative facet that substitutes for the one in the North case. David seems to adopt the strategy of multiplying the facets of distribution to draw attention away from the two main receivers of consignments, NE Grocery Ltd and Food Wholesalers Ltd, although these two delivery points still appear in Delivery Ltd Case. 
The actors in charge of transporting the counterfeit alcohol across the border between Ireland and the UK (David, James and Philip) seem to favour the strategy of using long chains of legitimate logistics networks, where alcohol can be easily concealed as a legitimate product (for example, water) and therefore can travel unobserved. In this respect, their strategy resembles the one of cigarette smuggling across Europe via the water route (Kupka and Tvrdá 2016; Di Nicola and Terenghi 2016), but it is different from the 'car trains' across the Schengen border in the Czech Republic (Kupka and Tvrdá 2016). The similarities and differences suggest that when smuggling across water, criminals need to rely on legitimate logistics companies, whereas terrestrial routes can be covered by cars, owned by the criminal group and therefore less exposed to detection. When comparing this criminal activity with other transit crimes, for example those described by Lavorgna in her analysis of wildlife trafficking (2014b), we notice that the transport and distribution scripts coincide perfectly, suggesting the existence of a proto-script (Leclerc et al. 2011) of transit crimes that is worth further investigations. The abuse/misuse of legitimate business by the criminals illustrates a clear interdependency between illicit and licit markets. A possible situational intervention could be the enforcement of the requirement for logistics firms to verify the content of consignments, especially in international transports.

Once delivered, the counterfeit alcohol seems to spread around a well-ramified selling network, on which we do not have, for the time being, enough information. However, given the fact that some people in charge of disposal (John, Sarah, Peter) and some places (Stockton on Tees, Norfolk) have emerged as very central in the network, we believe that further investigation is required to follow these threads and monitor the selling process. Together with people involved in disposal, the other main central actors are indeed those in charge of proceeds, who are also the main brokers between scenes together with David, who is mainly in charge of delivery. Sean came up as important for disposal and proceeds, while Philip and John seem to be the actors with an overview of the entire criminal process, managing the links across all scenes. More importantly, both Phillip and John occupy mostly liaison and gatekeeping roles, which are difficult roles to outsource. Whereas coordination can be left in the hands of other actors (such as David and Sean) because they only need to know about a specific scene, all the other roles, and especially liaison roles, require a general overview of the whole crime commission process.

The literature also suggests that the risky movement of money and commodities is usually the task of those in lower positions in the organization (Hancock and Laycock 2010): we found contradicting evidence in our case, because some of the people involved in money and commodity movements (David and Philip) score high on the centrality and brokerage measures, whereas Andrew and Steven, both involved in proceeds, do not score high on either betweenness or GF brokerage roles. This could indicate either that Andrew and Steven keep a low profile in the crime commission process to avoid the risk of being caught, or that the group is not highly hierarchically organized, and tasks are assigned to actors depending on their competences and resources (efficiency) rather than the need for secrecy. It could also be that some of these people, for example Sarah and Peter, who score high on betweenness centrality but are not directly connected to the other main actors, could be external agents acting as intermediaries who occasionally sell counterfeit alcohol on the web or to friends. Even in this role they still benefit from a high level of trust from the core network to be left in charge of disposal. Similar behaviours have been observed for 
tobacco smuggling and bootlegging in the UK (Antonopoulos and Hall 2016) and it would be interesting to investigate how they are recruited in the first place.

We can now evaluate the resilience of this network. Following Bouchard (2007), we believe the network shows a good level of elasticity, as it seems that once the Scottish route was disrupted, the English one was put in place to restore the connection between Ireland and the UK. The multiplication of the delivery facets also seems to indicate a good level of adaptivity, which relies on multiple actors, resources and locations. Overall, the crime seems to be committed by a small group of two pairs of brothers (John and Andrew, and Sean and Steven), friends with each other, who spread their activities across two countries with the help of another friend, David, in charge of distribution. None of these actors, apart from Andrew, has previous links to criminality; none has previous convictions or displays signs of an established criminal lifestyle. According to previous definitions of organized crime, our group does not fall into this category, although it shows a solid level of organization in the efficiency and resilience of the network.

In terms of advancing the literature on criminal networks, our analysis shows the importance of including multi-mode networks, because central actors are not always people but can also be legitimate organizations and locations, and multi-link networks, because differentiating between various types of connections facilitates the understanding of how the criminal procedure is organized, as indicated by Carley (2003) and Krebs (2002). We believe that by shifting the analysis from the nature of the group organization to the network of links between all the aspects of a crime commission process, the organizational structure, and its weakest links, become more detectable, easier to compare across protoand meta-scripts, and ultimately more prone to situational preventive measures. Our case, however, is not to be taken as representative of the market for counterfeit alcohol. Different case studies, of different scales or for different counterfeit products, may reveal possible roles of organized crime groups, as has been observed, for example, for food crimes (HM Government 2014). Ultimately, the research question about the possible involvement of organized crime groups in counterfeit markets remains, but it should be approached from the investigation of the crime commission process rather than the characteristics of such groups.

\section{Conclusions}

In this article we analysed a series of open investigations into the distribution of counterfeit alcohol across Ireland and UK. We use script analysis to identify the procedural steps required to perform the criminal activity, the actors involved in each step, the available resources, the activities performed and the locations in which the criminal process took place. We then reconstructed the multi-mode, multi-link social network that embeds the various entities involved in the crime process and performed a brokerage analysis of the actors that link the different scenes, coordinating and facilitating the performance of the criminal activity. In doing so, we were able to identify the deception points in the script where intervention and disruption strategies could be implemented.

With our analysis we have shown the importance of looking at criminal procedures without assuming a priori the existence of a hierarchical and monolithic criminal organization whose 
boundaries of affiliation and activities can be easily identified. More fruitful is to start with a specific crime commission process and observe the procedural steps required to perform it, the casting of actors and resources, and the locations in which activities take place and their timing. This is because it is difficult to draw a clear categorical distinction between illegitimate and legitimate activities: criminals may not be organized groups, but simply people who engage in temporary criminal activities alongside legitimate ones, and hide behind the façade of legitimate business, which gives them the required cover to manage the distribution of illicit products (Pearson and Hobbs 2001 and 2004; Lavorgna 2014b).

Focusing on the criminal steps and the networks that build around their performance seems a viable strategy to investigate the involvement and responsibilities of the actors that are variously connected to the crime investigation, and to identify the vulnerabilities within the structure and the process of the criminal activities. By proposing this perspective and this type of analysis, we hope future research can further investigate the peculiarities of markets in counterfeit products, but also compare and contrast the scripts of various markets of counterfeit products and of transit crimes in general.

\section{References}

Albanese, J. S., (2000), The causes of organized crime: do criminals organize around opportunities for crime or do criminal opportunities create new offenders?, Journal of contemporary criminal justice, 16/4: 409-423.

Antonopoulos, G. A., (2008), The Greek connection(s). The social organization of the cigarette-smuggling business in Greece, European Journal of Criminology, 5: 263-288.

Antonopoulos, G. A., and Hall, A., (2016), The Financial Management of the Illicit Tobacco Trade in The United Kingdom, British Journal of Criminology, 56: 709-728.

Ashby, M. P. J., (2015), Is metal theft committed by organized crime groups, and why does it matter?, Criminology \& Criminal Justice, 16/2: 141-157.

Benson, M. L., and Simpson, S. S., (2015), Understanding White-Collar Crime: an Opportunity Perspective, Criminology and Justice Studies, Routledge.

Borgatti, S. P., Everett, M. G. and Freeman, L. C., (2002), Ucinet 6 for Windows: Software for Social Network Analysis, Analytic Technologies, Harvard, MA.

Bouchard, M., (2007), On the Resilience of Illegal Drug Markets, Global Crime, 8/4: 325-344.

Bright, D. A., and Delaney, J. J., (2013), Evolution of a Drug Trafficking Network: Mapping Changes in Network Structure and Function Across Time, Global Crime, 14/2-3: 238-260.

Bright, D. A., Greenhill, C., Ritter, A., and Morselli, C., (2015), Networks within Networks: Using Multiple Link Types to Examine Network Structure and Identify Key Actors in a Drug Trafficking Operation, Global Crime, 16/3: 219-237. 
Bullock, K., Clarke, R. V., Tilley, N., (2010), Introduction, in Bullock, K., Clarke, R. V., Tilley, N., (Eds.), Situational prevention of organized crime, Devon: Willan Publishing.

Campana, P., (2011), Eavesdropping on the Mob: The Functional Diversification of Mafia Activities across Territories, European Journal of Criminology, 8/3:213-228.

Carley, K. M., (2003), Dynamic Network Analysis, in R. Breiger, K. Carley, P. Pattison, (Eds.), Dynamic Social Network Modelling and Analysis: Workshop Summary and Papers, 133-145. The National Academies Press.

Chiu, Y., Leclerc, B., and Townsley, M., (2011), Crime Script Analysis of Drug Manufacturing in Clandestine Laboratories. Implications for Prevention, British Journal of Criminology, 51: 355-374.

Cornish, D. B., (1994), The Procedural Analysis of Offending and its Relevance for Situational Prevention, in R. V. Clarke, (Ed.), Crime Prevention Studies, 2. Pp. 151-156, Criminal Justice Press.

Di Nicola, A., and Terenghi, F., (2016) Managing finances in the illicit tobacco trade in Italy, Trends in organized crime, 19/3-4: 254-272.

Eckblom, P., (2003), Organized crime and the conjunction of criminal opportunity framework, in A. Edwards and P. Gill, (Eds.) Transnational organized crime: Perspectives on global security. Pp. 242-263, Abingdon: Routledge.

Edwards, A., and Gill, P., (2002), Crime as enterprise, Crime Law and Social Change 37: 203223.

Edwards, A., and Levi, M., (2008), Researching the organization of serious crimes, Criminology and Criminal Justice, 8: 363-388.

Finckenauer, J. O., (2005) Problems of definition: what is organized crime? Trends in organized crime, 8/3: 63-83.

Freeman, L. C., (1979), Centrality in social networks: Conceptual clarification, Social Networks, 1: 215-39.

Gimenez-Salinas Framis, A., (2013), Illegal networks or criminal organizations: Power, roles and facilitators in four cocaine trafficking structures, in C. Morselli, (Ed.), Crime and Networks, 131-148. London: Routledge.

Gould, R. V., and Fernandez, R. M., (1989), Structures of Mediation: a Formal Approach to Brokerage in Transaction Networks, Sociological Methodology, 19: 89-126.

Hancock, G., Laycock, G., (2010), Organized crime and crime scripts: prospects for disruption, in K. Bullock, R. V. Clarke, N. Tilley, (Eds.), Situational prevention of organized crime. Pp. 172-192, Devon: William Publishing. 
HM Government, (2014), Elliott Review into the Integrity and Assurance of Food Supply Networks - Final Report. A National Food Crime Prevention Framework. https://assets.publishing.service.gov.uk/government/uploads/system/uploads/attachment data/file/350726/elliot-review-final-report-july2014.pdf (Accessed 30/05/2018).

Hobbs, D., and Antonopoulos G. A., (2014), How to research organised crime. In L. Paoli, (Ed.), The Oxford handbook of organised crime. New York: Oxford University Press.

Kleemans, E. R., (2007), Organized crime, transit crime, and racketing, Crime \& Justice, 35 : 165-215.

Klerks, P., (2001), The Network Paradigm Applied to Criminal Organizations: Theoretical Nitpicking or a Relevant Doctrine for Investigators? Recent Developments in the Netherlands, Connections, 24/ 3: 53-65.

Koschade, S., (2006), A Social Network Analysis of Jemaah Islamiyah: the Applications to Counterterrorism and Intelligence, Studies in Conflict \& Terrorism, 29/6: 559-575.

Kotelnikova, Z., (2014), Consumption of counterfeit alcohol in contemporary Russia: the role of cultural and structural factors, HSE Basic Research Program working papers. Series Sociology. WP BRP 47/SOC/2014. Available at: https://www.hse.ru/data/2014/08/06/1314159630/47SOC2014.pdf.

Kotelnikova, Z., (2017), Explaining Counterfeit Alcohol Purchases in Russia, Alcoholism: clinical and experimental research, 41/4: 810-819.

Krebs, V. E., (2002), Mapping Terrorist Networks, Connections, 24/3: 43-52.

Kupka, P., and Tvdrá, K., (2016) "Cigarettes smuggling for greenhorns": recent patterns of illegal tobacco trade in the Czech Republic, Trends in organized crime, 19/3-4: 218-235.

Lang, K., Vali, M., Szücs, S., Adany, R., McKee, M. (2006), The composition of surrogate and illegal alcohol products in Estonia, Alcohol Alcohol 41: 446-450.

Lavorgna, A., (2014a), The online trade in counterfeit pharmaceuticals: New criminal opportunities, trends and challenges, European Journal of Criminology, 12/2: 226-241.

Lavorgna, A., (2014b), Wildlife trafficking in the Internet age, Crime Science, 3: 5.

Lavorgna, A., and Sergi, A., (2016) Serious, therefore organized? A critique of the emerging "cyber-organized crime" rhetoric in the United Kingdom, International Journal of Cyber Criminology, 10/2: 170-187.

Leclerc, B., Wortley, R., Smallbone, S., (2011), Getting into the script of adult child sex offenders and mapping out situational preventive measures, Journal of Research in Crime and Delinquency, 48/2: 209-237. 
Leclerc, B., and Wortley, R., (2014), The reasoning Criminal: twenty-five years on, In B. Leclerc, and R. Wortley (Eds.), Cognition and crime: Offender decision-making and script analyses. Pp. 1-12, London: Routledge.

Lord, N., Spencer, J., Albanese, J., and Elizondo, C. F., (2017), In pursuit of food system integrity: the situational prevention of food fraud enterprise, European Journal on Criminal Policy and Research, 23: 483.

Lord, N., Spencer, J., Bellotti, E. and Benson, K. (2017) 'A script analysis of the distribution of counterfeit alcohol across two European jurisdictions', Trends in Organized Crime, 20: 1-21.

McKee, M., Suzcs, S., Sarvary, A., Adany, R., Kiryanov, N., Saburova, L., Tomkins, S., Andreev, E., Leon, D. A. (2005), The composition of surrogate alcohols consumed in Russia, Alcoholism: clinical and experimental research, 29: 1884-1888.

Morselli, C., (2010), Assessing Vulnerable and Strategic Positions in a Criminal Network Journal of Contemporary Criminal Justice, 26: 382-392.

Morselli, C., and Roy, J., (2008), Brokerage qualifications in ringing operations, Criminology, 46/1: 71-98.

Morselli, C., Giguire, C., and Petit, K., (2007), The efficiency/security trade-off in criminal networks, Social Networks, 29/1: 143-153.

Naylor, R. T., (2003), Towards a General Theory of Profit-Driven Crimes, British Journal of Criminology, 43: 81-101.

OHIM, (2015), Situation Report on Counterfeiting in the European Union. A joint project between Europol and the Office for Harmonization in the Internal Market, https://oami.europa.eu/ohimportal/documents/11370/80606/2015+Situation+Report+on+ Counterfeiting+in+the+EU.

Oliver, K., (2014), Covert networks: structures, processes and types, Mitchell Centre Working Paper, University of Manchester.

Pearson, G., Hobbs, D., (2001), Middle Market Drug Distribution. Home Office Research Study 227. London: Home Office Research and Statistics Directorate.

Pearson, G., Hobbs, D., (2004), E is for enterprise: Middle level drug markets in ecstasy and stimulants, Addiction Research \& Theory, 12/6: 565-576.

Schank, R. C., and Abelson, R., (1977), Scripts, Plans, Goals, and Understanding. An inquiry into human knowledge structures, New Jersey: Lawrence Earlbaum Associates.

Schwartz, D. M., and Rouselle, T., (2009), Using Social Network Analysis to Target Criminal Networks, Trends in Organized Crime, 12: 188-207. 
Spencer, J., Lord, N., Benson, K. and Bellotti, E. (2018) "C' is for Commercial Collaboration: Enterprise and Structure in the 'Middle Market' of Counterfeit Alcohol Distribution', Crime, Law and Social Change.

Varese, F., (2010), What is organized crime?, in F. Varese, (Ed.), Organized Crime: Critical Concepts in Criminology. Pp. 1-35, London: Routledge. 